\title{
Efficient Oil/Water Separation By Zwitterionic Poly(sulfobetaine methacrylate)@Cu(OH)2 Nanoneedle Array-coated Copper Meshes With Superwetting and Antifouling Properties
}

Huaqiang He, Housheng Jiang, Chen Chen, Like Ouyang, Wei Jiang, Shaojun Yuan a,

Low-carbon Technology \& Chemical Reaction Engineering Lab, College of Chemical Engineering, Sichuan University, Chengdu 610065, China

Corresponding author: S.J. Yuan, E-mail: ysj@scu.edu.cn, Tel: +86-28-85405201 (Office), Fax: +86-28-85405201 


\section{S1 Experimental}

S1.1 Materials. The 300-mesh copper membranes with the wire thickness of $50 \mu \mathrm{m}$ (purity 99.9\% were bought from Shengzhuo Metal Wire Mesh Co. (Anping city, China). The sulfobetaine methacrylate (SBMA, 99\%) 3-(trimethoxysilyl)propyl methacrylate (TMSPMA, 98\%), 2,2'-azobisisobutyronitrile (AIBN) and $\left(\mathrm{NH}_{4}\right)_{2} \mathrm{~S}_{2} \mathrm{O}_{8}$ and chemical oxygen demand (COD) measurement reagents, such as $\mathrm{K}_{2} \mathrm{Cr}_{2} \mathrm{O}_{7}, \mathrm{H}_{2} \mathrm{SO}_{4}(98 \%)$, $\mathrm{HgSO}_{4}, \mathrm{Ag}_{2} \mathrm{SO}_{4}$, and $\left(\mathrm{NH}_{4}\right)_{2} \mathrm{Fe}\left(\mathrm{SO}_{4}\right)_{2} .6 \mathrm{H}_{2} \mathrm{O}$ were purchased from Aladdin Industrial Co. (Shanghai, China), and were used as received. Other chemicalreagents, such as $\mathrm{NaOH}, \mathrm{HCl}$, isopropyl, ethanol, toluene, acetone and methanol were purchased from Kelong Chem. Co. (Chengdu, China), and were used as received. The oil samples, such as olive oil, isooctane, hexane, dichloromethane and kerosence were obtained from Sigma-Aldrich Chem. Co. (St. Louis, MO). The oilfield wastewater and oilfield produced liquids were kindly provided by Sinopec Northwest Oilfield Branch (Urumchi, China). All the deionized water used in the experiments was produced on a commercial reverse osmosis $(\mathrm{RO})$ workstation.

S1.2 COD measurement. An aliquot $2.5 \mathrm{~mL}$ of each testing sample was taken in COD vials. $1.5 \mathrm{~mL}$ of $0.125 \mathrm{~mol} \cdot \mathrm{L}^{-1} \mathrm{~K}_{2} \mathrm{Cr}_{2} \mathrm{O}_{7}, 3.5 \mathrm{~mL}$ of $\mathrm{H}_{2} \mathrm{SO}_{4}$, and a pinch of $\mathrm{HgSO}_{4}$ and $\mathrm{Ag}_{2} \mathrm{SO}_{4}$ were added. The vials were closed tightly and were digested at $150^{\circ} \mathrm{C}$ for $2 \mathrm{~h}$ and then were cooled to room temperature. These contents were transferred into the conical flask and 2-3 drops of ferroin indicator were added, followed by being titrated against freshly prepared $0.1 \mathrm{~mol} \cdot \mathrm{L}^{-1}\left(\mathrm{NH}_{4}\right)_{2} \mathrm{Fe}\left(\mathrm{SO}_{4}\right)_{2}$ solution. The titration end point was determined by the appearance of reddish brown color. For comparison purpose, deionized water blank was also run simultaneously. COD was calculated using following Equation S1: 


$$
\operatorname{COD}=\frac{(\mathrm{A}-\mathrm{B}) \times \mathrm{M} \times 8 \times 1000}{\mathrm{~V}}
$$

where, A is volume of titrant used for the sample, B is volume of the titrant used for blank deionized water, $\mathrm{M}$ is the molar concentration of ferrous ammonium sulfate and V denotes volume of the sample taken. 


\section{S2 Results and discussion}

Table S1 The comparison of the oil/water separation performance of different superhydrophilic and underwater superoleophobic membranes

\begin{tabular}{|c|c|c|c|c|}
\hline Membrane & $\begin{array}{l}\text { Oily wastewater } \\
\text { type }\end{array}$ & $\begin{array}{c}\text { Flux } \\
\left(\mathrm{KL} / \mathrm{m}^{2} \cdot \mathrm{h}\right)\end{array}$ & $\begin{array}{l}\text { Residual oil content } \\
\text { (ppm) }\end{array}$ & Reference \\
\hline PAA-g-PVDF & Emulsions & $0.72-2.32$ & $<40$ & 1 \\
\hline $\begin{array}{l}\text { Sulfobetaine silanized } \\
\text { stainless steel wire }\end{array}$ & Emulsions & $170-3300$ & $<73$ & 2 \\
\hline $\begin{array}{l}\text { PMPC-grafted steel } \\
\text { mesh }\end{array}$ & Emulsions & $0.61-0.88$ & $<3.2$ & 3 \\
\hline PMAPS-g-PVDF & Emulsions & 1.2 & $<10$ & 4 \\
\hline $\begin{array}{l}\text { Polyacrylonitrile } \\
\text { membranes }\end{array}$ & Emulsions & 2.2 & $<10$ & 5 \\
\hline $\begin{array}{c}\mathrm{Cu}(\mathrm{OH})_{2} \text {-coated copper } \\
\text { mesh }\end{array}$ & $\begin{array}{l}\text { Oil/water } \\
\text { mixture }\end{array}$ & $127-158$ & $<60$ & 6 \\
\hline PANI-modified PVDF & Emulsions & $1.72-4.49$ & $<320$ & 7 \\
\hline $\begin{array}{l}\text { Zeolite-coated stainless } \\
\text { steel meshes }\end{array}$ & $\begin{array}{l}\text { Oil/water } \\
\text { mixture }\end{array}$ & 90 & $<10$ & 8 \\
\hline $\begin{array}{c}\text { TiO2@CuO-coated } \\
\text { copper mesh }\end{array}$ & Emulsions & 10.5 & $<26$ & 9 \\
\hline $\begin{array}{l}\text { PSBMA@CHNNA- } \\
\text { coated copper mesh }\end{array}$ & Emulsions & 15.6 & $<\mathbf{2 3}$ & $\begin{array}{l}\text { This } \\
\text { study }\end{array}$ \\
\hline
\end{tabular}




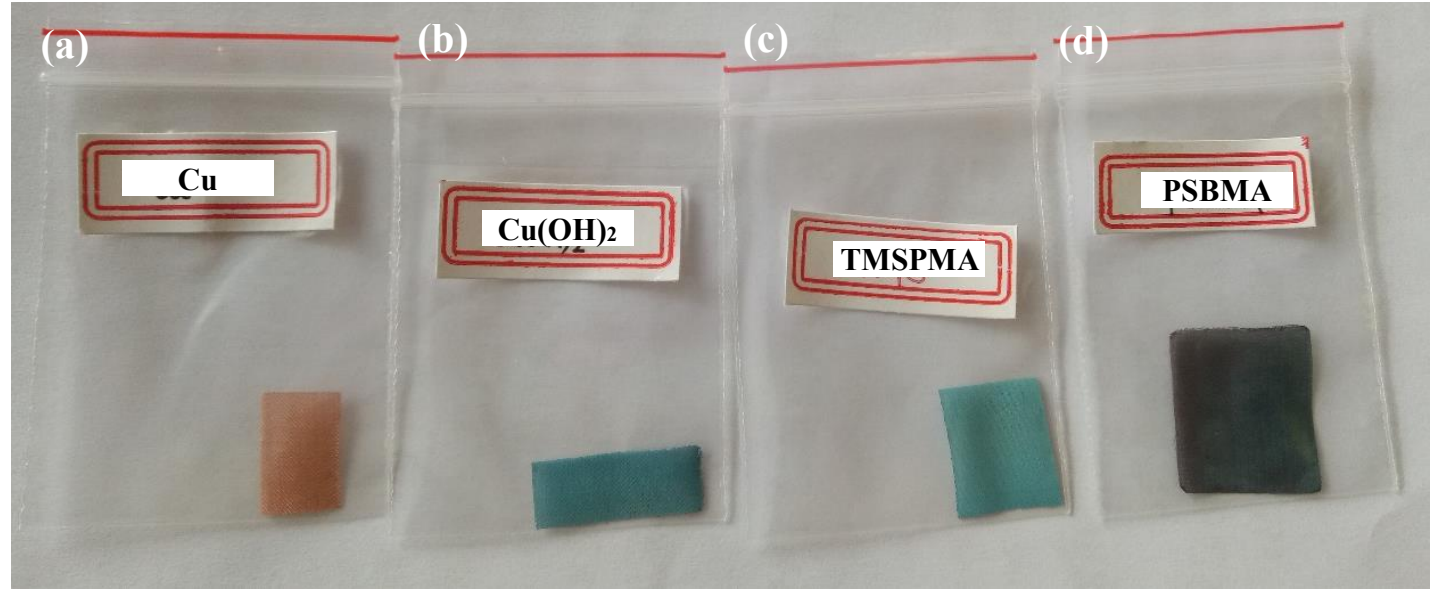

Fig. S1 The optical pictures of the (a) pretreated copper, (b) CHNNA-covered, (c) $\mathrm{Cu}$ TMSPMA and (d) PSBMA@CHNNA-coated meshes. 


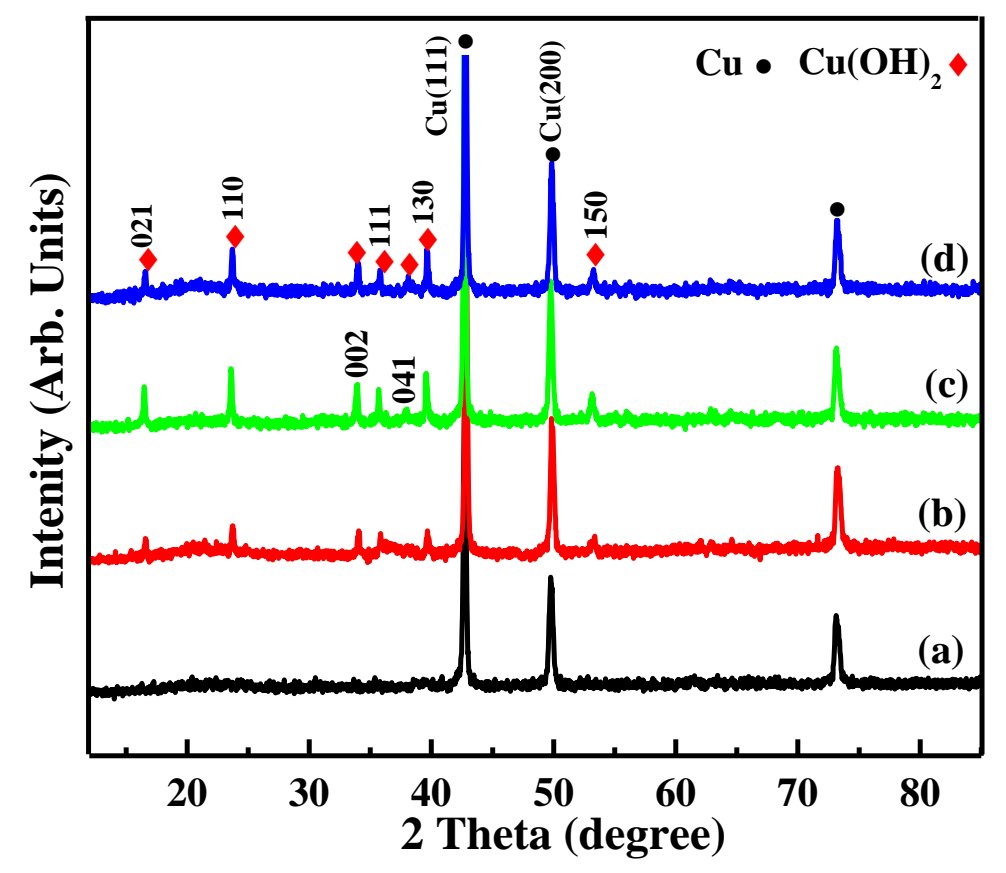

Fig. S2 XRD patterns of the (a) pretreated $\mathrm{Cu}$ mesh, (b) CHNNA-coated $\mathrm{Cu}$ mesh after 10 min of oxidation reaction, (c) CHNNA-coated $\mathrm{Cu}$ mesh after 20 min of oxidation reaction, and (d) CHNNA-coated $\mathrm{Cu}$ mesh after 30 min of oxidation reaction 


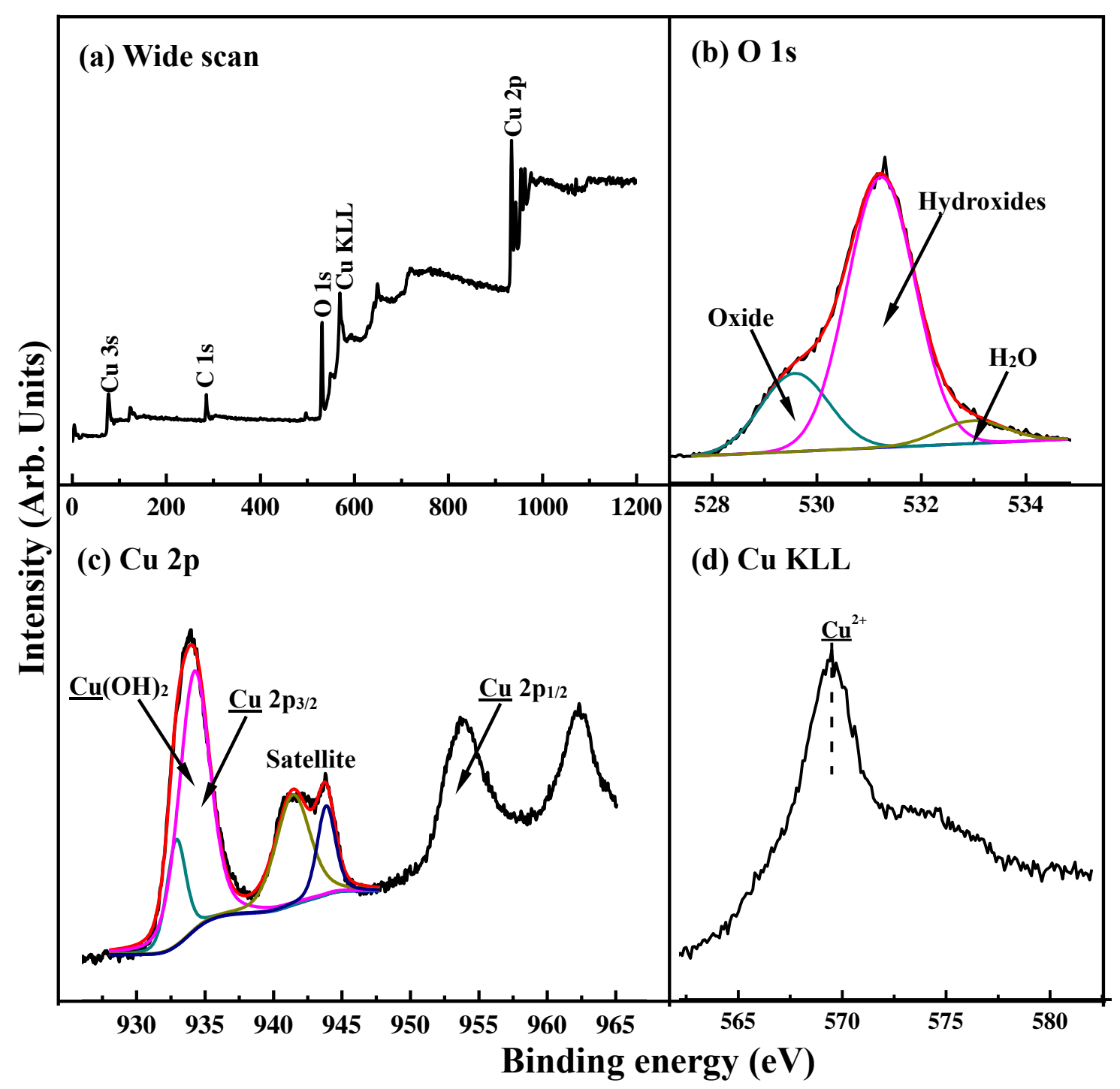

Fig. S3 The (a) wide scan, (b) O 1s, (c) Cu 2p and (d) Cu KLL core-level XPS spectra of the CHNNA-covered copper mesh obtained by $30 \mathrm{~min}$ of chemical oxidation. 


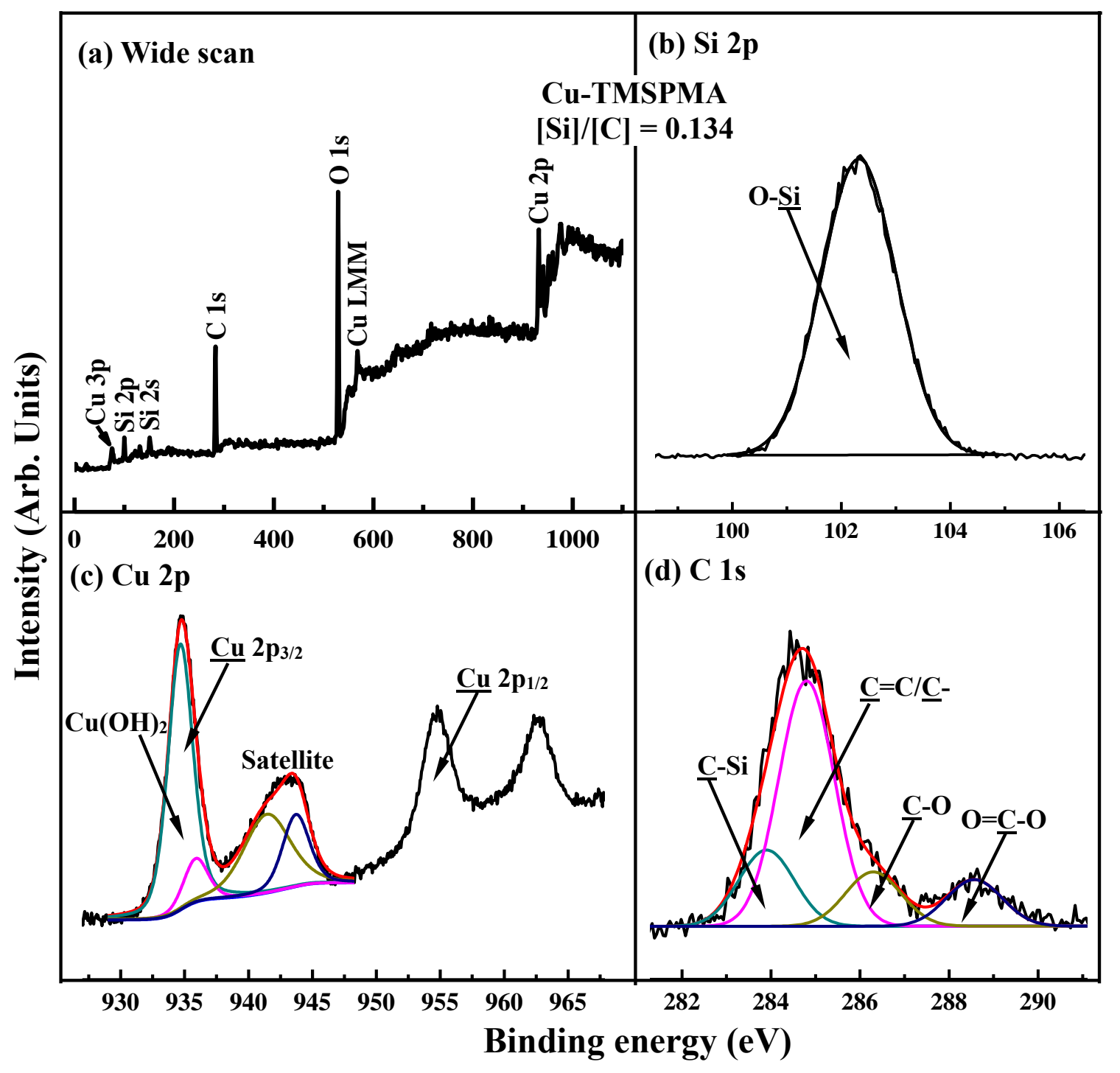

Fig. S4 The XPS spectra of the Cu-TMSPMA copper meshes: (a) wide scan, (b) Si $2 \mathrm{p},(\mathrm{c}) \mathrm{Cu} 2 \mathrm{p}$, and (d) C $1 \mathrm{~s}$ 


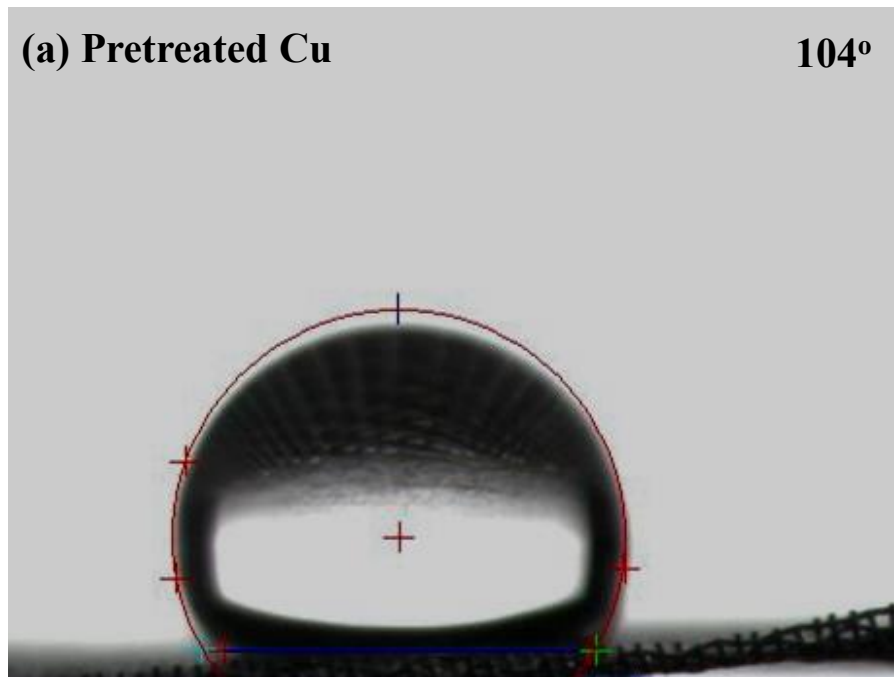

(b) Pretreated Cu

$18^{\circ}$

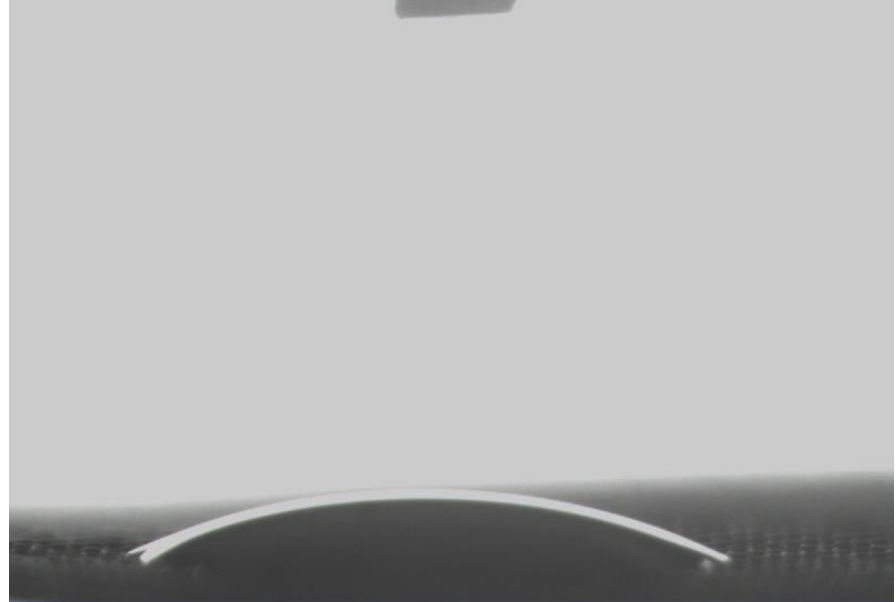

(c) Cu-TMSPMA

$126^{\circ}$

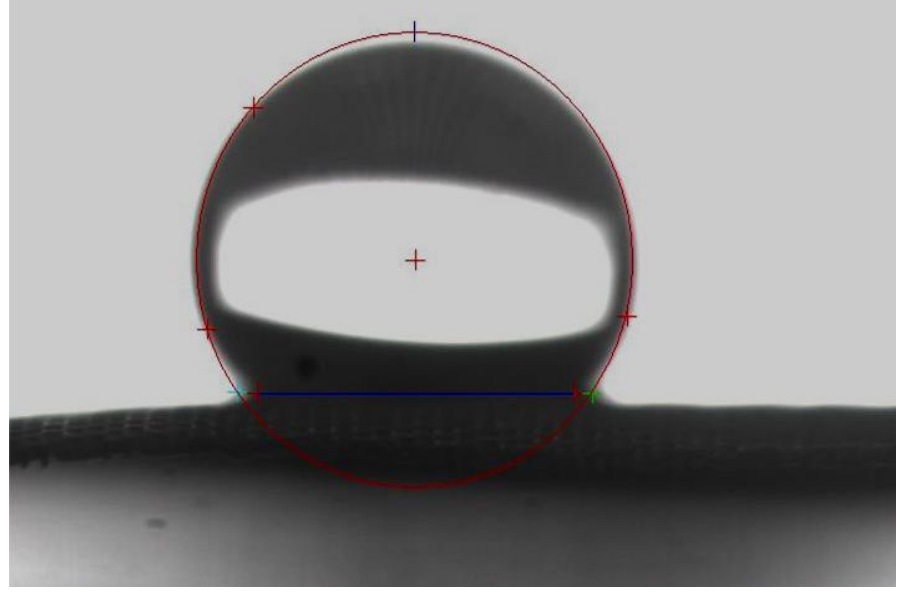

Fig. S5 (a) Static water contact angle on the pristine pretreated copper meshes in air, (b) oil contact angle for kerosene on the pristine pretreated copper mesh, and (c) static water contact angles of $\mathrm{Cu}$-TMSPMA meshes in air. 


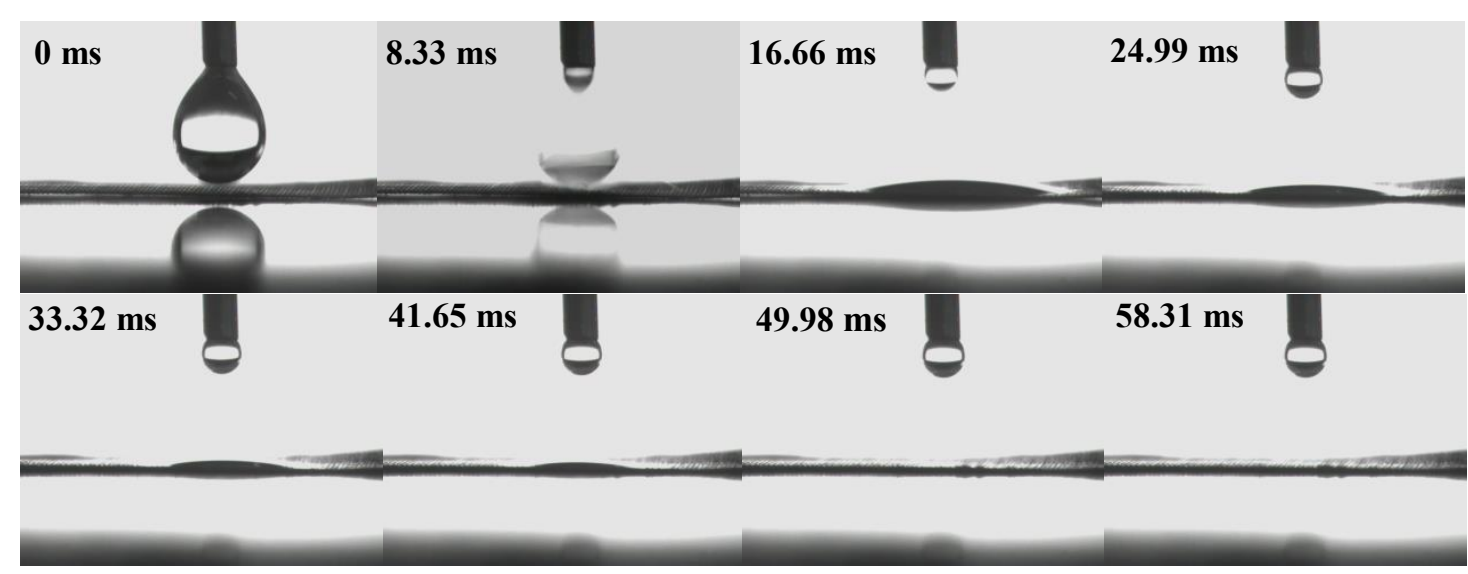

Fig. S6 Snapshots of spreading and permeating behaviors for a water droplet contacting on the CHNNA-covered copper meshes in air. The photographs were captured using high-speed photography with $8.33 \mathrm{~ms}$ per frame. 


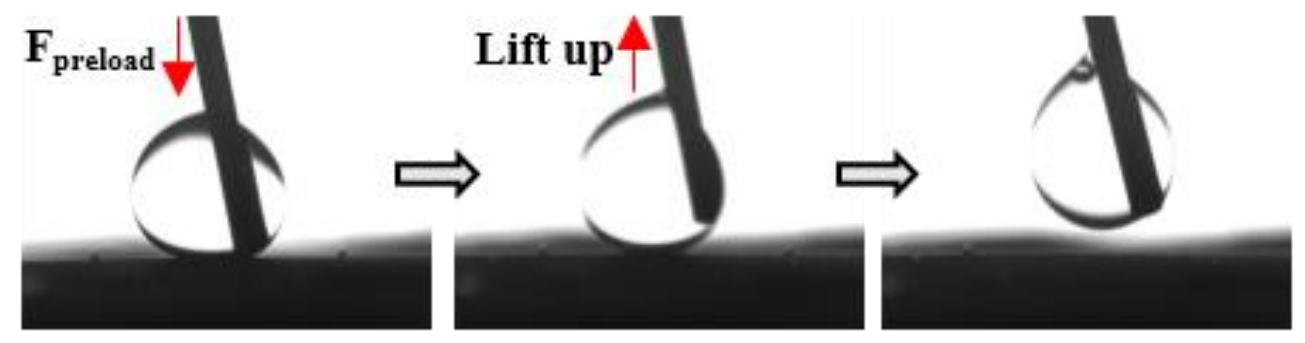

Fig. S7 The low adhesion force of the kerosene droplets on the as-synthesized PSBMA@CHNNA-coated copper meshes as illustrated by underwater oil contact angles measurement 


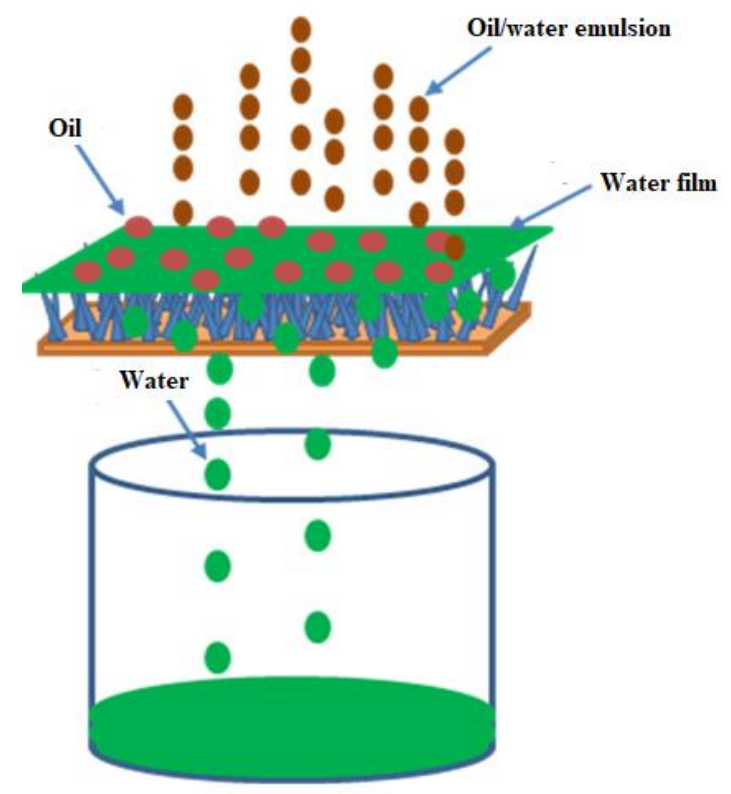

Fig. S8 Schematic illustration of the oil/water separation process of the PSBMA@CHNNA-coated copper meshes 


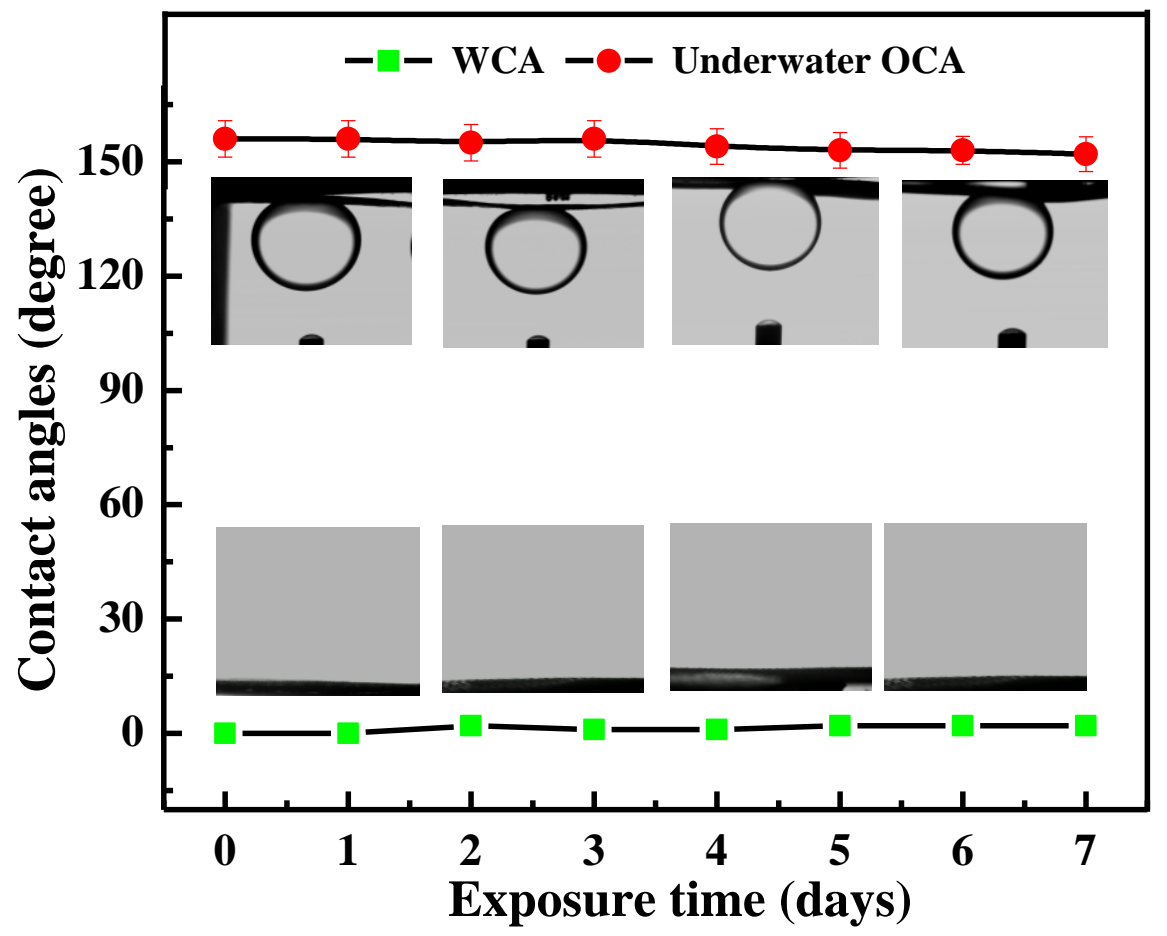

Fig. S9 The evolution profiles in water contact angle and underwater oil contact angles with increasing exposure time in deionized water and the corresponding optical images in water contact angels and underwater oil contact angles on the zwitterionic PSBMA@CHNNA-coated copper meshes. 


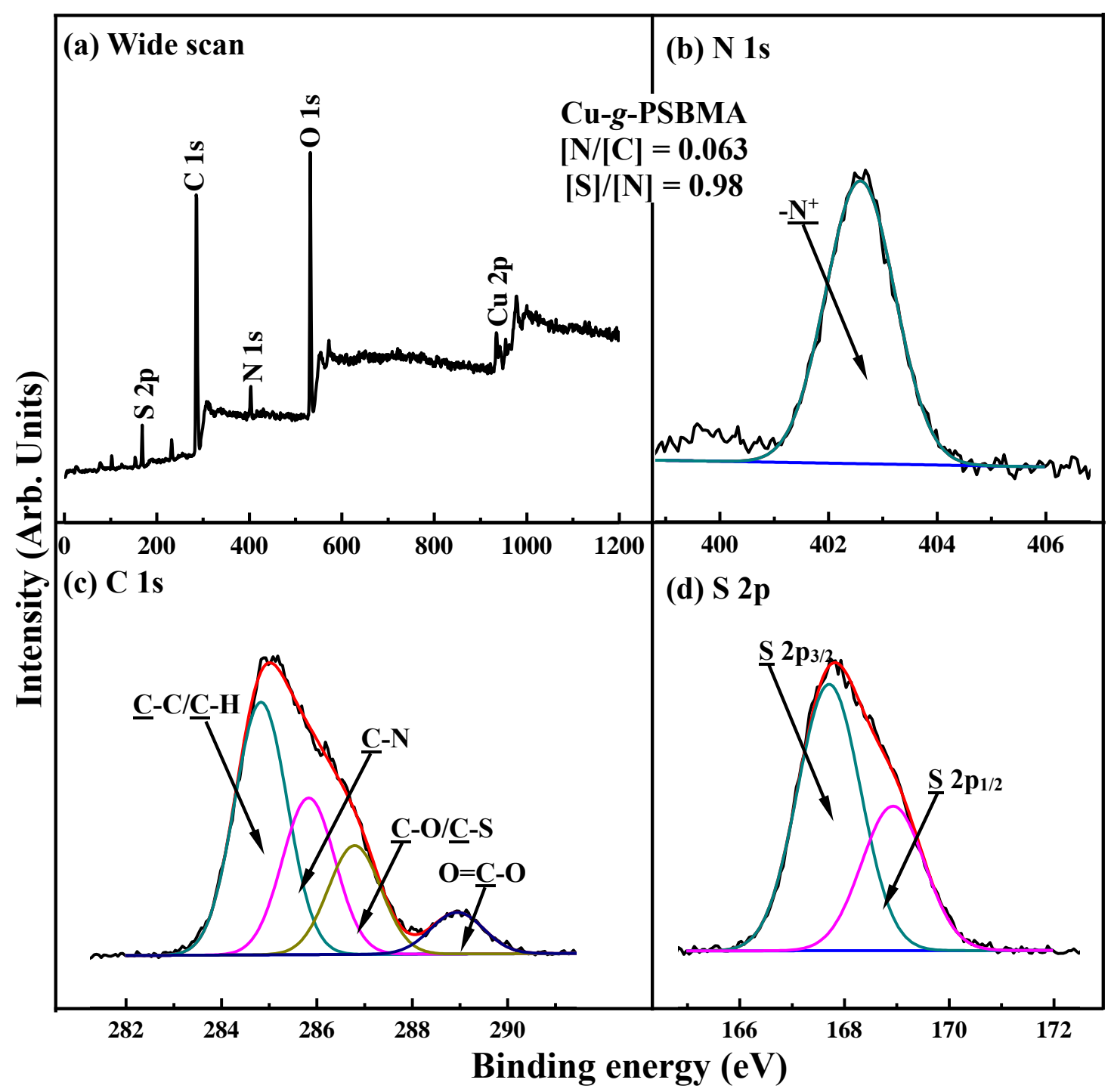

Fig. S10 The (a) wide scan, (b) N 1s, (c) C 1s and S 2p core-level XPS spectra of the PSBMA@CHNNA-coated mesh membrane after 10 cycles of oil/water separation operations. 


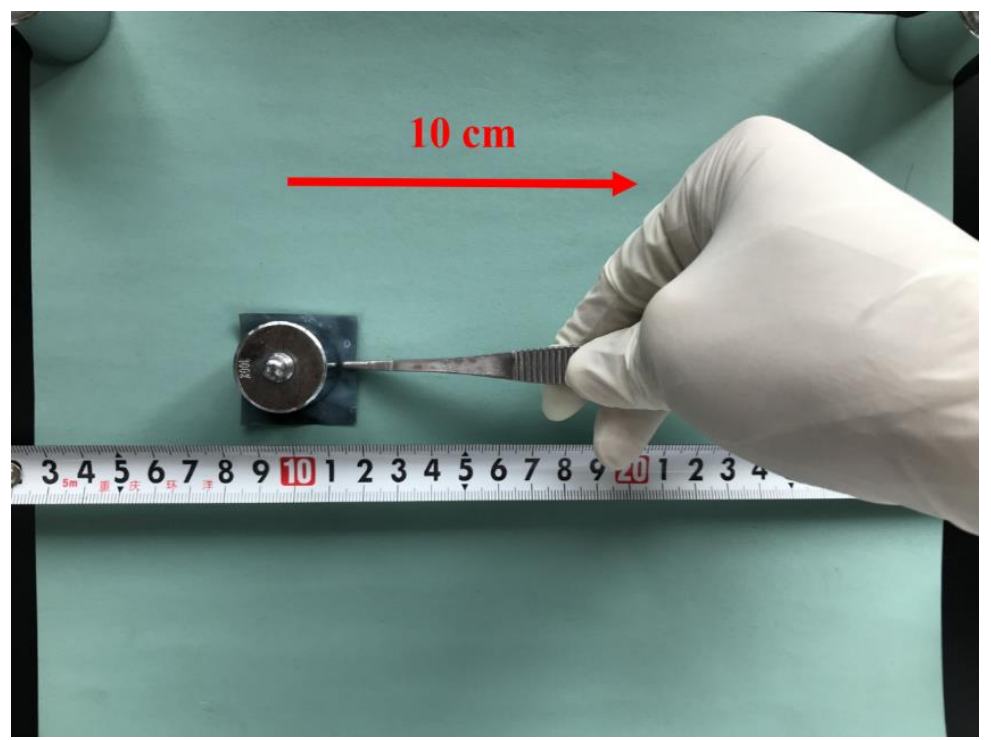

Fig. S11 The opitcal images to illustrate the abrasion experiment of the as-synthesized PSBMA@CHNNA-coated copper meshes on a 1200-grit abrasive paper. A 100-g balane weight was placed on the mesh surfaces. 


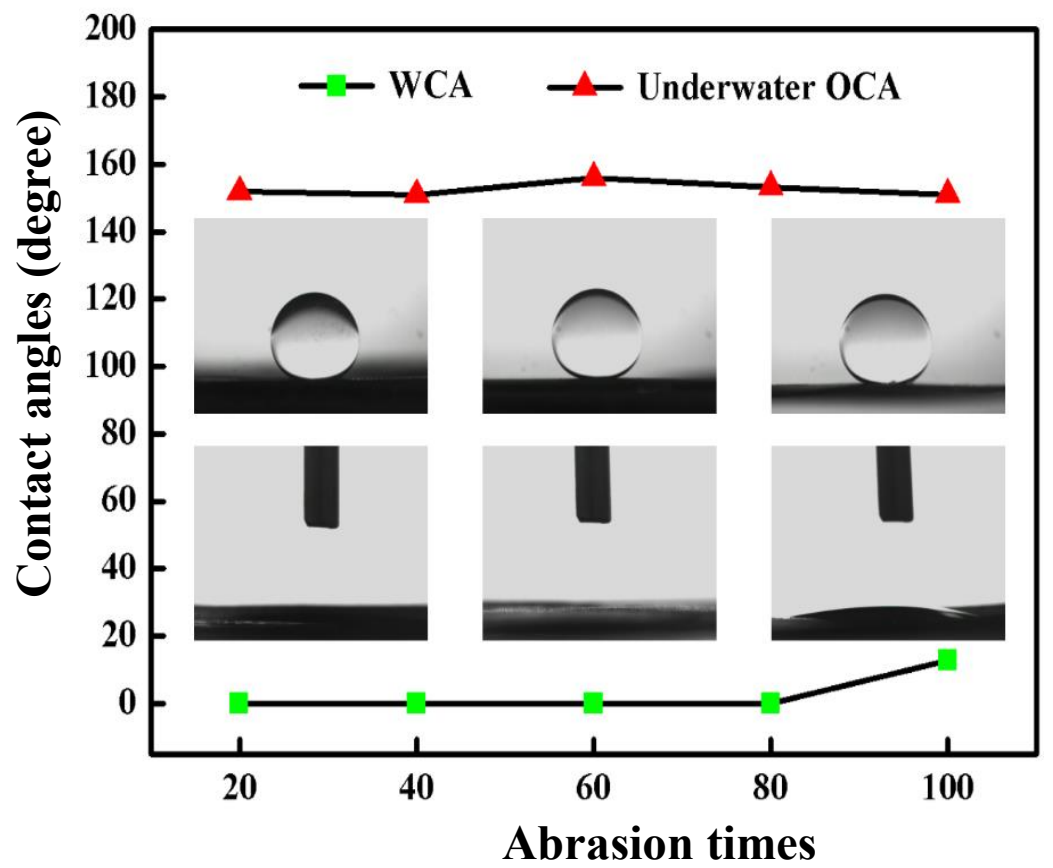

Fig. S12 The change in water and underwater oil contact anges of the zwitterionic PSBMA@CHNNA-coated copper meshes as function of abrasive times in the abrasion test 


\section{Reference}

1. Zhang, W.; Zhu, Y.; Liu, X.; Wang, D.; Li, J.; Jiang, L.; Jin, J., Salt-induced fabrication of superhydrophilic and underwater superoleophobic PAA-g-PVDF membranes for effective separation of oil-in-water emulsions. Angewandte Chemie International Edition 2014, 53 (3), 856860.

2. Huang, K.-T.; Yeh, S.-B.; Huang, C.-J., Surface modification for superhydrophilicity and underwater superoleophobicity: applications in antifog, underwater self-cleaning, and oil-water separation. ACS applied materials \& interfaces 2015, 7 (38), 21021-21029.

3. He, K.; Duan, H.; Chen, G. Y.; Liu, X.; Yang, W.; Wang, D., Cleaning of oil fouling with water enabled by zwitterionic polyelectrolyte coatings: overcoming the imperative challenge of oil-water separation membranes. ACS nano 2015, 9 (9), 9188-9198.

4. Zhu, Y.; Zhang, F.; Wang, D.; Pei, X. F.; Zhang, W.; Jin, J., A novel zwitterionic polyelectrolyte grafted PVDF membrane for thoroughly separating oil from water with ultrahigh efficiency. Journal of Materials Chemistry A 2013, 1 (18), 5758.

5. Zhang, F.; Gao, S.; Zhu, Y.; Jin, J., Alkaline-induced superhydrophilic/underwater superoleophobic polyacrylonitrile membranes with ultralow oil-adhesion for high-efficient oil/water separation. Journal of Membrane Science 2016, 513, 67-73.

6. Zhang, F.; Zhang, W. B.; Shi, Z.; Wang, D.; Jin, J.; Jiang, L., Nanowire-haired inorganic membranes with superhydrophilicity and underwater ultralow adhesive superoleophobicity for high-efficiency oil/water separation. Advanced Materials 2013, 25 (30), 4192-4198.

7. Liu, M.; Li, J.; Guo, Z., Polyaniline coated membranes for effective separation of oil-in-water emulsions. Journal of colloid and interface science 2016, 467, 261-70.

8. Wen, Q.; Di, J.; Jiang, L.; Yu, J.; Xu, R., Zeolite-coated mesh film for efficient oil-water separation. Chem. Sci. 2013, 4 (2), 591-595.

9. Ji, J.; He, H.; Chen, C.; Jiang, W.; Raza, A.; Zhang, T.-J.; Yuan, S., Biomimetic Hierarchical TiO2@CuO Nanowire Arrays-Coated Copper Meshes with Superwetting and Self-Cleaning Properties for Efficient Oil/Water Separation. ACS Sustainable Chemistry \& Engineering 2019, 7 (2), 2569-2577. 